\title{
Osseous Metaplasia in Ovarian Endometrial Cyst: A Case Report
}

\author{
Learta Asani ${ }^{1}$, Dafina Nikolova ${ }^{2 *}$, Katerina Madzunkova ${ }^{3}$, Vlatko Karanfilovski ${ }^{4}$, Stefan Pandilov ${ }^{4}$ and \\ Vesna Janevska ${ }^{4}$ \\ ${ }^{1}$ City General Hospital $8^{\text {th }}$ September, Skopje, Republic of North Macedonia \\ ${ }^{2}$ University Clinic of Gastroenterohepatology, Skopje, Republic of North Macedonia
}

${ }^{3}$ University Clinic of Gynecology and Obstetrics, Skopje, Republic of North Macedonia

${ }^{4}$ Institute of Pathology, Faculty of Medicine, Skopje, Republic of North Macedonia

*Corresponding author: Dafina Nikolova, University Clinic of Gastroenterohepatology, Skopje, Republic of North Macedonia

\section{ARTICLE INFO}

Received: 㓞 November 27, 2019

Published: December 11, 2019

Citation: Learta Asani, Dafina Nikolova, Katerina Madzunkova, Vlatko Karanfilovski, Stefan Pandilov, Vesna Janevska. Osseous Metaplasia in Ovarian Endometrial Cyst: A Case Report. Biomed J Sci \& Tech Res 23(5)-2019. BJSTR. MS.ID.003959.

\section{ABSTRACT}

Osseous metaplasia in the female genital tract is a rare condition with unknown clinical importance and unknown etiology. We report a rare case of osseous metaplasia in an ovarian endometrial cyst, and comment to a chronic inflammation as a possible etiology.

Keywords: Osseous metaplasia; Ovarian endometrial cyst; Chronic inflammation

Abbreviations: CA-125: Cancer Antigen 125, CA-19-9: Cancer Antigen 19-9, CK7: Cytokeratin 7; MUC16: Mucin 16; ROS: Reactive Oxygen Species; MMPs: Matrix Metalloproteinases; BMPs: Bone Morphogenetic Proteins; FOP: Fibrodysplasia Ossificans Progressiva; MSCs: Mesenchimal Stem Cells; ERa: Estrogen Receptor Alpha

\section{Introduction}

Osseous metaplasia has been described in many tissues, most commonly in musculoskeletal and central nervous system, followed by soft tissue organs [1,2]. In the female genital tract osseous metaplasia is reported as a rare condition in cervix and vagina, and it is more often found in endometrium [2-4]. In ovary it is a rare entity and is usually associated with cystic teratoma, mucinous cystadenoma [5], papillary serous cystadenocarcinoma [6], endometrioid adenocarcinoma [7] and thecoma [8]. We present a rare case of ovarian endometriosis with osseous metaplasia of the endometrial cyst.

\section{Case Report}

A 25 years old female was presented with heaviness and pain in lower abdomen for last 2 months. The patient gave history of normal menstrual cycles, nulliparity and menarche on 9 years. Physical examination noted the presence of painful cystic mass in the right adnexal region, closely connected to the posterior wall of uterus. On ultrasonography left ovary was with normal dimensions and was unremarkable, but right ovary showed three cystic formations (diameter: $34 \mathrm{~mm}, 57 \mathrm{~mm}, 42 \mathrm{~mm}$ ) with hypoechoic appearance. A hyperechoic small mural mass was present in one of them. Working diagnosis of benign cystic tumor of right ovary was made, not excluding endometrioma. Additional laboratory tests showed elevated CA-125 (107U/ml) and CA-19-9 (57.4 U/ml). All other blood parameters including serum calcium level were in normal range. Laparotomy was performed at the University Clinic of Gynecology and Obstetrics in Skopje and an extirpation of cystic formation was done. Operative material and peritoneal fluid taken during the surgery were sent for histopathological examination at the Institute of Pathology in Skopje. Cytological examination was negative.

Gross examination of the operative material revealed artificially opened trilocular cystic lesion measuring $9.5 \times 6 \times 0.5 \mathrm{~cm}$. The outer 
surface of the cyst was smooth, but luminal side was rough and dark brown colored. Some blood was found in the cyst. The thickness of its wall varied from 0.2 to $0.5 \mathrm{~cm}$. Microscopic examination showed compressed ovary tissue and endometrial cyst, composed of collagenous wall, endometrial epithelium and a lot of hemosiderin laden macrophages. The epithelium showed some metaplastic changes, but it was CK7 and vimentin positive (Figures 1a \& 1b). Some endometrial stroma, immunoreactive for CD10 antibody, was found in one area. Lymphocytic inflammatory infiltrate was found beneath the epithelium in various amounts (Figure 1a). In some areas scattered polimorphonuclears among the lymphocytes were also found. High amount of hemosiderin laden macrophages were located in the cystic wall, together with some cholesterol crystals (Figure 1c) and metaplastic bone. Cortical bone with Haversian canals and cancellous bone were recognized. Osteoblastic rimming, osteoclasts laden with hemosiderin and calcification of the bone were also visible (Figures 1d-1f). A year after the surgery the patient is in well health with regular postoperative ultrasound findings.

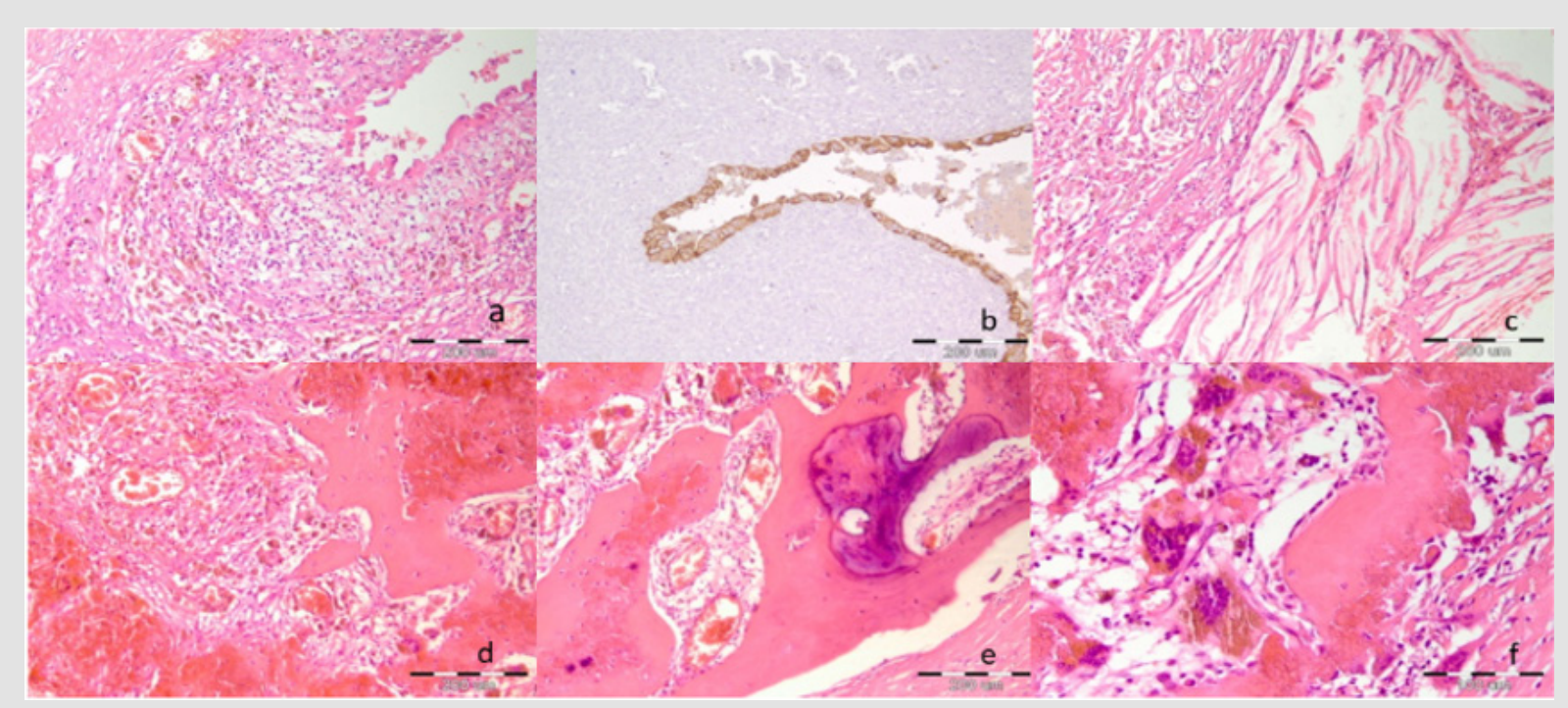

Figure 1: Microphotographs of ovarian endometrioma with bone formation. a) Cystic wall composed of fibrous tissue, loosely connective tissue reach with lymphocytes and hemosiderin laden macrophages and epithelium (H.E. 10x10) b) CK7 positivity of the epithelium (immunostaining with antibody against CK7, 10x10) c) Cholesterol crystals surrounded by inflammatory cells (H.E. 10x10) d) Metaplastic bone closely connected to the granulation tissue at one side and blood collection at the other side (H.E. 10x10) e) Cortical bone with calcification (H.E. 10x10) f) A bony trabeculae rimmed by osteoblasts (right) and osteoclasts in neighborhood laden with hemosiderin (left) (H.E.10x10).

\section{Discussion}

Endometriosis is a chronic condition with the most common locations in ovaries, fallopian tubes, and tissue around the uterus and ovaries [9] and is associated with a chronic inflammation and scar tissue and adhesions forming [10]. Ultrasound is non-invasive method for diagnosing endometriosis, especially large cystic lesions. Lesions identifiable on ultrasound include hypoechogenic unilocular or multilocular cysts with or without regular contours or with or without mural nodules [11]. Differential diagnosis of endometrioma includes dermoid cyst, hemorrhagic cyst, neoplasm, ovarian abscess, and ectopic pregnancy [12]. The situation is more complicated when the adnexal mass contains calcifications or bone segments, which together with elevated CA125 and CA 19-9 values may suggest a malignant process. In such cases osseous metaplasia can be a reason for a misdiagnosis at ultrasound examination, when a cystic lesion containing bone may be diagnosed as a malignant or benign tumor [13].

Carbohydrate antigen 19-9 (CA19-9) and Cancer antigen 125 (CA-125) are mainly increased in gastrointestinal tumors, but they can also be increased in other types of malignancies, in some benign conditions, and endometriosis as well [14-18]. Bone formation is found in some neoplastic lesions of the ovaries [58], but it is also found in some non-neoplastic conditions of ovary as is endometriosis [19]. Generally, endometriosis is considered as an estrogen-dependent chronic inflammatory disease [18]. Despite morphological changes are well recognized, the exact and detailed pathogenesis of endometriosis is still not known, as well as the exact role of immunological and inflammatory processes in its persistence and development [19]. Some authors pointed the presence of local microenvironment reach with chronic inflammatory cells and their secreted cytokines that cause chronic inflammation of surrounding tissue [20,21]. According Lin YH et all, the cystic fluid within an endometrioma is rich with proinflammatory cytokines, iron, reactive oxygen species (ROS), growth factors, and matrix metalloproteinases (MMPs). These cystic fluid contents could diffuse into surrounding ovarian tissue and cause chronic inflammation, promoting fibrosis and adhesion formation through myofibroblast differentiation and reduced blood supply [22]. 
More recently, a few studies explained the role of bone morphogenetic proteins (BMPs) (family of growth factors) in many pathological conditions that have inflammation as hallmark in their pathophysiology and pointed the BMPs involvement in inflammatory phenotype of endothelial cells in atherosclerosis, vascular calcification and process of endothelial to mesenchymal transition [23]. BMPs upregulate expression of adhesion molecules promoting leukocyte adhesion, with consecutive chronic inflammation and tissue fibrosis [23]. The pathogenesis of osseous metaplasia in ovary is also uncertain, but it appears to be an unusual reaction to tissue damage and repair [24]. For some authors the possible explanation is overgrowth of coexisting coalesced psammomatous calcifications, which may arise from spontaneous or induced necrosis of the tissue [24]. For others they are related to secretion BMPs [24]. Bone morphogenetic protein (BMP) ligands are able to induce bone and cartilage development and are found to have a complex role in the embryonic development of many organ systems $[25,26]$. Overactive BMP signaling pathway is considered to be the underlying cause of the ectopic chondrogenesis, ectopic bone formation, and joint fusion seen in patients with Fibrodysplasia ossificans progressiva - FOP [25]. In this condition, ectopic bone is thought to originate from mesenchimal stem cells (MSCs) which lie dormant in soft tissues and differentiate into osteogenic cells [24].

Athanasios et all demonstrated that ectopic endometrium showed intense cytoplasmic immunoreactivity to BMP-6 in both epithelium and stroma. This study also showed that BMP6 expression is highly associated with strong expression of estrogen receptors (ERa) which may be at least partly involved in the mechanisms of attachment, survival and expansion of endometriosis [27]. BMP may promote the co-development of endometriosis and chronic inflammation as two complementary and closely connected conditions [22,27]. As we discussed above, the areas of endometriosis bleed each month, resulting in chronic inflammation and creating a microenvironment reach with BMPs that may induce osseous metaplasia of multipotential stromal stem cells with psammoma body and bone formation [25]. In our case paucicellular colagenous wall was covered with a layer of granulation and loosely connective tissue in which beside the macrophages remarkable amount of lymphocytes were found. Bone formation was closely connected to the granulation tissue at one side and blood collection at the other side. This finding strongly suggests bone formation in a process of inflammation and reparation.

\section{Conclusion}

Osseous metaplasia in endometrial cyst of ovary is extremely rare condition which should be considered in the diagnostic procedure of cystic ovarian lesions, so that no misdiagnosis occurs. Due to its unclear clinical importance and unknown etiology and to understand the full pathogenesis of this condition further research is needed on this topic.

\section{References}

1. Shehab D, Elgazzar AH, Collier BD (2002) Heterotopic ossification. Journal of Nuclear Medicine 43(3): 346-353.

2. Alsaqobi A, Al Brahim N (2018) Osseous Metaplasia of the Cervix: A Rare Transformation Can Mimic a Tumor Literature Review. Case Reports in Pathology p. 4.

3. Landim FM, Tavares JM, de Melo Braga DN, da Silva JE Jr, Bastos Filho JB, et al. (2009) Vaginal osseous metaplasia. Arch Gynecol Obstet 279(3): 381-384.

4. Patil SB, Narchal S, Paricharak DG, More SS (2013) Endometrial Osseous Metaplasia: Case Report with Literature Review. Ann Med Health Sci Res (Suppl1): S10-S12.

5. Zahn CM, Kendall BS (2001) Heterotopic bone in the ovary associated with a mucinous cystadenoma. Mil Med 166(10): 915-917.

6. Bosscher J, Barnhill D, O'Connor D, Doering D, Nash J, et al. (1990) Osseous metaplasia in ovarian papillary serous cystadenocarcinoma. Gynecol Oncol 39(2): 228-231.

7. Mukonoweshuro P, Oriowolo A (2005) Stromal osseous metaplasia in a low-grade ovarian adenocarcinoma. Gynecol Oncol 99(1): 222-224.

8. Morizane M, Ohara N, Mori T, Murao S (2003) Ossifying luteinized thecoma of the ovary. Arch Gynecol Obstet 267(3): 167-169.

9. Bulletti C, Coccia ME, Battistoni S, Borini A (2010) Endometriosis and infertility. J Assist Reprod Genet 27(8): 441-447.

10. Kennedy S, Bergqvist A, Chapron C, D'Hooghe T, Dunselman G, et al. (2005) ESHRE guideline on the diagnosis and management of endometriosis. Hum Reprod 20(10): 2698-2704.

11. Bazot M, Malzy P, Cortez A, Roseau G, Amouyal P, et al. (2007) Accuracy of transvaginal sonography and rectal endoscopic sonography in the diagnosis of deep infiltrating endometriosis. Ultrasound Obstet Gynecol 30(7): 994-1001.

12. Hsu AL, Khachikyan I, Stratton P (2010) Invasive and non-invasive methods for the diagnosis of endometriosis. Clin Obstet Gynecol 53(2): 413-419.

13. Singh AK, Gogoi P, Diwaker P, Adhlakha B, Gayatree A, et al. (2018) Osseous metaplasia of ovarian cyst: a rare case report. International Surgery Journal Sep 5(9): 3164-3166.

14. Pavai S, Yap SF (2003) The clinical significance of elevated levels of serum CA 19-9. Med J Malaysia Dec 58(5): 667-672.

15. Nagata H, Takahashi K, Yamane Y, Yoshino K, Shibukawa T, et al. (1989) Abnormally high values of CA 125 and CA $19-9$ in women with benign tumors. Gynecol Obstet Invest 28(3): 165-168.

16. Shiau CS, Chang MY, Chiang CH, Hsieh CC, Hsieh TT (2003) Ovarian endometrioma associated with high serum CA-125 levels. Chang Gung Med J 26: 695-969.

17. Bast RC, Xu FJ, Yu YH, Barnhill S, Zhang Z, et al. (1998) CA 125: the past and the future. The International Journal of Biological Markers 13(4): 179-187.

18. Seeber B, Sammel MD, Fan X, Gerton GL, Shaunik A, et al. (2008) Panel of markers can accurately predict endometriosis in a subset of patients. Fertil Steril 89(5): 1073-1081.

19. Su WH, Wang PH, Chang SP (2002) Ovarian stone A case report. J Repord Med 47(4): 329-331.

20. Wu MH, Hsiao KY, Tsai SJ (2015) Endometriosis and possible inflammation markers. Gynecology and Minimally Invasive Therapy 4(3): 61-67.

21. Králíčková M, Fiala L, Losan P, Tomes P, Vetvicka V, et al. (2018) Altered Immunity in Endometriosis: What Came First? Immunol Invest 47(6): 569-582. 
22. Lin YH, Chen YH, Chang HY, Au HK, Tzeng CR, et al. (2018) Chronic Niche Inflammation in Endometriosis-Associated Infertility: Current Understanding and Future Therapeutic Strategies. Int J Mol Sci 19(8).

23. Wu DH, Hatzopoulos AK (2019) Bone morphogenetic protein signaling in inflammation. Experimental Biology and Medicine 244(2): 147-156.

24. Lanzafame S, Nicolosi GA, Caltabiano R (2007) Bilateral massive osseous metaplasia in ovaries: "ovarian stones". Gynecol Surg 4(3): 191-193.

25. Zhang H, Bradley A (1996) Mice deficient for BMP2 are nonviable and have defects in amnion/chorion and cardiac development. Development 122(10): 2977-2986.

ISSN: 2574-1241

DOI: 10.26717/BJSTR.2019.23.003959

Dafina Nikolova. Biomed J Sci \& Tech Res

(C) This work is licensed under Creative Commons Attribution 4.0 License

Submission Link: https://biomedres.us/submit-manuscript.php
26. Mishina Y, Kamiya N (20011) New insights on the roles of BMP signaling in bone A review of recent mouse genetic studies. Biofactors 37(2): 7582.

27. Athanasios F, Afrodite N, Effstratios P, Demetrios K (2012) Coexpression of bone morphogenetic protein 6 with estrogen receptor in endometriosis. Arch Gynecol Obstet 285(4): 1001-1007.

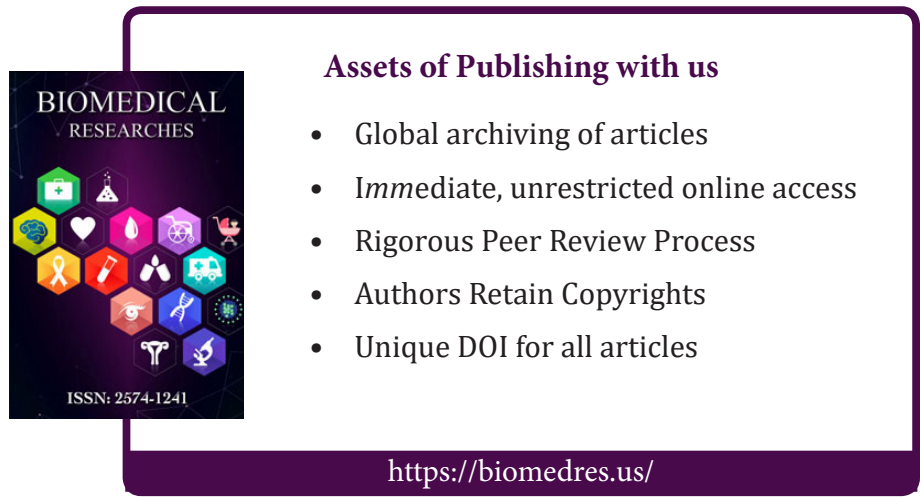

